\title{
Highly efficient human serum filtration with water-soluble nanoporous nanoparticles
}

This article was published in the following Dove Press journal:

International Journal of Nanomedicine

18 November 2010

Number of times this article has been viewed

\section{Antonella Pujia' \\ Francesco De Angelis ${ }^{1,2}$ \\ Domenica Scumaci ${ }^{3}$ \\ Marco Gaspari ${ }^{3}$ \\ Carlo Liberale ${ }^{1,2}$ \\ Patrizio Candeloro' \\ Giovanni Cuda ${ }^{3}$ \\ Enzo Di Fabrizio1,2}

'BIONEM Laboratory, Department of Experimental and Clinical Medicine, University of Catanzaro "Magna Graecia”, Germaneto (CZ), Italy; 2IIT, Italian Institute of Technology, Genova, Italy; ${ }^{3}$ Proteomics and Mass Spectrometry Laboratory, Department of Experimental and Clinical Medicine, University of Catanzaro "Magna Graecia”, Germaneto (CZ), Italy
Correspondence: Enzo Di Fabrizio BIONEM Laboratory, Department of Experimental and Clinical Medicine, University of Catanzaro "Magna Graecia”, Viale Europa 88100, Germaneto (CZ), Italy

Tel +3909613694225

Fax +39096I 3694073

Email enzo.difabrizio@iit.it
Background: Human serum has the potential to become the most informative source of novel biomarkers, but its study is very difficult due to the incredible complexity of its molecular composition. We describe a novel tool based on biodegradable nanoporous nanoparticles (NPNPs) that allows the harvesting of low-molecular-weight fractions of crude human serum or other biofluids. NPNPs with a diameter of $200 \mathrm{~nm}$ and pore size of a few $\mathrm{nm}$ were obtained by ultrasonication of nanoporous silicon. When incubated with a solution, the NPNPs harvest only the molecules small enough to be absorbed into the nanopores. Then they can be recovered by centrifugation and dissolved in water, making the harvested molecules available for further analyses.

Results: Fluorescence microscopy, gel electrophoresis, and mass spectrometry were used to show the enrichment of low-molecular-weight fraction of serum under physiological conditions, with a cut-off of $13 \mathrm{kDa}$ and an enrichment factor $>50$.

Conclusion: From these findings, we conclude that ability to tune pore size, combined with the availability of hundreds of biomolecule cross-linkers, opens up new perspectives on complex biofluid analysis, discovery of biomarkers, and in situ drug delivery.

Keywords: nanoporous silicon, nanoparticle, biomarker discovery, human serum proteomics, harvesting

\section{Background}

The search for novel tools for early diagnosis is one of the major issues in medical research. The discovery of biomarkers in biological fluids and blood is especially challenging due to the tremendous number of biomolecular species, which differ by many orders of magnitude in their relative abundance. ${ }^{1,2}$ Of the several approaches proposed in the last few years, the study of the proteome seems to hold the greatest potential. ${ }^{2,3}$ Proteomics is a quickly developing area of biochemical investigation. The basic aim of proteomic analysis is the identification of specific protein patterns from cells, tissues, and biological fluids related to physiological or pathological condition. ${ }^{2,4}$ It provides a different view from that of gene expression profiling, which does not evaluate posttranscriptional and post-translational modifications, or protein compartmentalization and half-life changes (eg, ubiquitination and proteosome-driven degradation). All these characteristics make the protein profile much more complex but more informative than gene expression profiling. Several approaches can be used to perform proteomic analysis; among these, the most common are methods based on 2D-polyacrylamide gel electrophoresis (2D-PAGE) and mass spectrometry (MS). ${ }^{5-9}$

It is now well accepted that the low-molecular-weight (LMW), low-abundance fraction of biological fluids might contain the most informative source of novel 
biomarkers. The conventional analytical methods mentioned above do not seem to reach a sufficient degree of resolution and sensitivity to reliably detect and identify LMW and low-abundance peptides. Therefore, research has recently focused on the development of innovative devices that are able to enrich this fraction of body fluid proteome, making it available for use in common analytical tools.

Harvesting and enrichment of candidate biomarkers from complex protein mixtures can be pursued in different ways. Usually, in the plasma or serum, in which albumin and immunoglobulin alone account for $>90 \%$ of total protein content, these species are conventionally removed prior to 2D-PAGE and MS by immunoaffinity depletion columns. However, it must be emphasized that many potentially informative biomarkers, represented by very small peptides noncovalently associated with the carrier protein albumin, are lost following this procedure. Many commercial albumin removal kits based on different methods are available, but it has been demonstrated that they can cause loss of several low-abundance proteins, including albuminome. ${ }^{10-12}$ Moreover, most of these sieving/filtering systems do not allow sufficient flexibility of the whole process. Therefore, alternative approaches are urgently needed. Nanotechnology methods appear to offer a promising and powerful strategy for overcoming these limitations. ${ }^{13-16}$

Discovered over 40 years ago, porous silicon (PSi) has attracted increasing attention in many fields of research for its interesting features. In particular, the demonstration of its biodegradability in physiological environments has opened up new perspectives for biomedical application. ${ }^{17}$ The desired dissolution rate can be obtained through the accurate control of the morphology, pore size, and $\mathrm{pH}$. The typical dissolution rate in alkaline conditions ranges from a few minutes to up to a few days. Moreover, the well-known functionalization processes of the porous surface provide further control of bioreactivity and hydrophobicity. ${ }^{18-21}$ Various surface derivatization has been reported in the literature and hundreds of different cross-linking agents are now available to selectively bind the target molecules. ${ }^{22}$

In this paper, we present a direct approach to harvesting the LMW fraction of a complex solution that relies on 3 important properties of silicon nanoporous nanoparticles (NPNPs): (a) they can act as nanosponges and absorb small molecules depending on nanopore size; (b) they can be separated from solution through efficient centrifugation (the nanoparticle density is higher than that of the solvent); (c) they can be dissolved in water. This last property is relevant because the filtration process can be carried out in physiological solution, without the need for introducing particular solvents, which can contaminate, denaturate, or degrade the potential biomarkers. The whole process is depicted in Figure 1 (Figures $1 \mathrm{a}-\mathrm{c}$ fabrication process and Figures $1 \mathrm{c}-\mathrm{h}$ harvesting process). The starting solution is incubated with NPNPs which, bcause of size-exclusion, can absorb only the LMW fraction into the nanopore. Afterwards, NPNPs can easily be recovered from solution by means of centrifugation, and resuspended in water, or other solvents in which they can be dissolved. The harvested molecules are then available, in their native state, for further analyses. This easy, cheap, and fast process enables the harvesting of peptides $<13 \mathrm{kDa}$ from raw serum.

Modern biology demands not only fast and easy techniques but also full compatibility with existing protocols. The present approach can be mixed and matched with the majority of current investigation protocols.

\section{Material and methods}

NPNPs were fabricated by ultrasonication of a thin film of nanoporous silicon. ${ }^{13-24}$ PSi was obtained by anodization of a boron-doped silicon wafer (resistivity 5-10 $\Omega \mathrm{cm}$ ) of [100] crystal orientation, using an electrolyte binary mixture of hydrofluoric acid (25\%), water (25\%), and ethanol (50\%). Applied constant current density was $10 \mathrm{~mA} / \mathrm{cm}^{2}$ for 5 minutes at $25^{\circ} \mathrm{C}$. Samples were rinsed in deionized water, then in ethanol and pentane. The PSi film was oxidized in an oven at $200^{\circ} \mathrm{C}$ for 2 hours. In order to obtain NPNPs, the PSi film was sonicated in dimethylformamide for about $60 \mathrm{~min}-$ utes and then, after washes in ethanol, ultrasonicated ( $5 \mathrm{~W}$ ) in water for 10 minutes at a constant temperature of $4^{\circ} \mathrm{C}$, and finally filtered to eliminate impurities $>500 \mathrm{~nm}$.

An ad hoc protein mixture was prepared by mixing 50\% (v/v) human serum albumin (MW 66,000 Da; SigmaAldrich, St. Louis, Missouri, USA); 30\% (v/v) bovine plasma gamma globulin (heavy chain MW 45,000 Da; light chain MW 30,000 Da; Biorad, Berkeley, California, USA); and 20\% (v/v) aprotinin (6,500 Da; Sigma-Aldrich). All proteins were dissolved at a concentration of $1 \mathrm{mg}$ / $\mathrm{mL}$ in $100 \mathrm{mM}$ sodium phosphate buffer and 9\% (w/v) sodium chloride $\mathrm{pH} 7.4$ (PBC) to reproduce physiological conditions.

Human serum was obtained from a healthy anonymous male donor and collected in accordance with Human Proteome Organization (HUPO) plasma proteome project guidelines. ${ }^{25}$ Approximately $8 \mathrm{~mL}$ of blood were drawn by venipuncture and collected in tubes without additive and allowed to clot at room temperature for 40 minutes. 


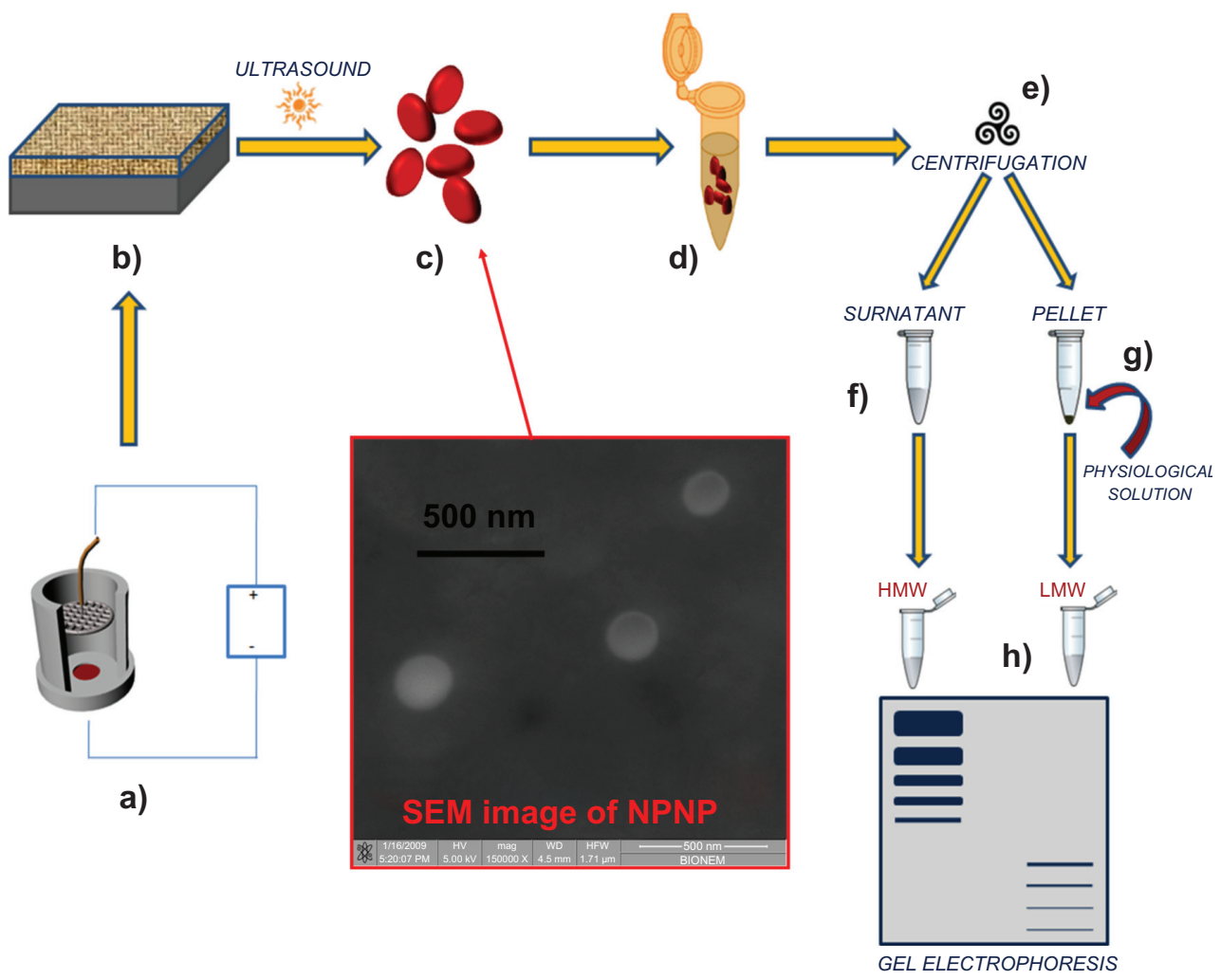

Figure I Pictorial description of the whole process from nanoparticles fabrication to splitting: (a) anodization of silicon wafer to produce porous silicon film; (b) porous silicon film on silicon substrate; (c) nanoporous nanoparticles (NPNPs) fabricated by ultrasonication; (d) incubation of the nanoparticles with biological fluid; (e) centrifugation and wash; (f) supernatant; $(\mathrm{g})$ pellet (physiological solution is added to dissolve it); (h) low-molecular-weight (LMW) harvesting and enrichment is demonstrated on a gel electrophoresis. The middle panel shows a scanning electron microscope image of nanoparticles.

Abbreviation: $\mathrm{HMW}$, high molecular weight.

The sample was centrifuged within 2 hours of collection at $1300 \times \mathrm{g}$ for 10 minutes, aliquoted into silicon tubes, and stored at $-80^{\circ} \mathrm{C}$.

\section{Results and discussion}

The fabricated NPNPs were deposited onto a glass substrate and characterized using scanning electron microscopy (SEM) and fluorescence microscopy. The results are reported in Figure 2. The pores of the particles are too small to be shown by SEM (Figures $2 \mathrm{~A}$ and $\mathrm{B}$ ), but the typical emission spectrum peak at around $620 \mathrm{~nm}$ (Figures $2 \mathrm{C}$ and D) indicates a pore size of about $2-3 \mathrm{~nm}$ (excitation wavelength $408 \mathrm{~nm}$ ). The nanoparticle diameter is about $200 \mathrm{~nm}$, and it can be adjusted by changing the power and duration of the sonication process.

We studied the interactions of the nanoparticles with complex biological fluids in different environmental conditions. Here we report 3 experiments with fluids of increasing complexity in order to show the splitting capability of the NPNPs:

1. Experiment 1. Interaction with 1 component solution: small dyes of different MWs.
2. Experiment 2. Interaction of a complex mixture of proteins with a wide range of MWs simulating a biological fluid.

3. Experiment 3. Interaction with crude human serum.

In the first experiment, NPNPs were incubated with

2 solutions of fluorescent polymer of different MWs

(6 $\mathrm{kDa}$ and $14 \mathrm{kDa}$ dextran-fluorescein isothiocyanate [FITC] $10 \mathrm{mg}$, NPNP $5 \mathrm{mg}$, water $10 \mathrm{~mL}, 1$ hour). After incubation, the NPNPs were separated from supernatant (centrifugation), dropped on a slide, dried, and analyzed with fluorescence microscopy. The results are summarized in Figure 3. Optical and fluorescence images collected on the NPNPs incubated with polymers of 14 and $6 \mathrm{kDa}$ are reported in upper and lower panels, respectively; for higher MW polymer there is no trace of absorption, and only a weak blue fluorescence coming from salt residue is visible. In contrast, green fluorescence emitted by NPNPs incubated with the lower MW polymer indicates good absorption.

After incubation and centrifugation, the recovered NPNPs can be dissolved in water at a rate depending on the temperature and acidity of the medium. At $\mathrm{pH} 8$ and $90^{\circ} \mathrm{C}$, 

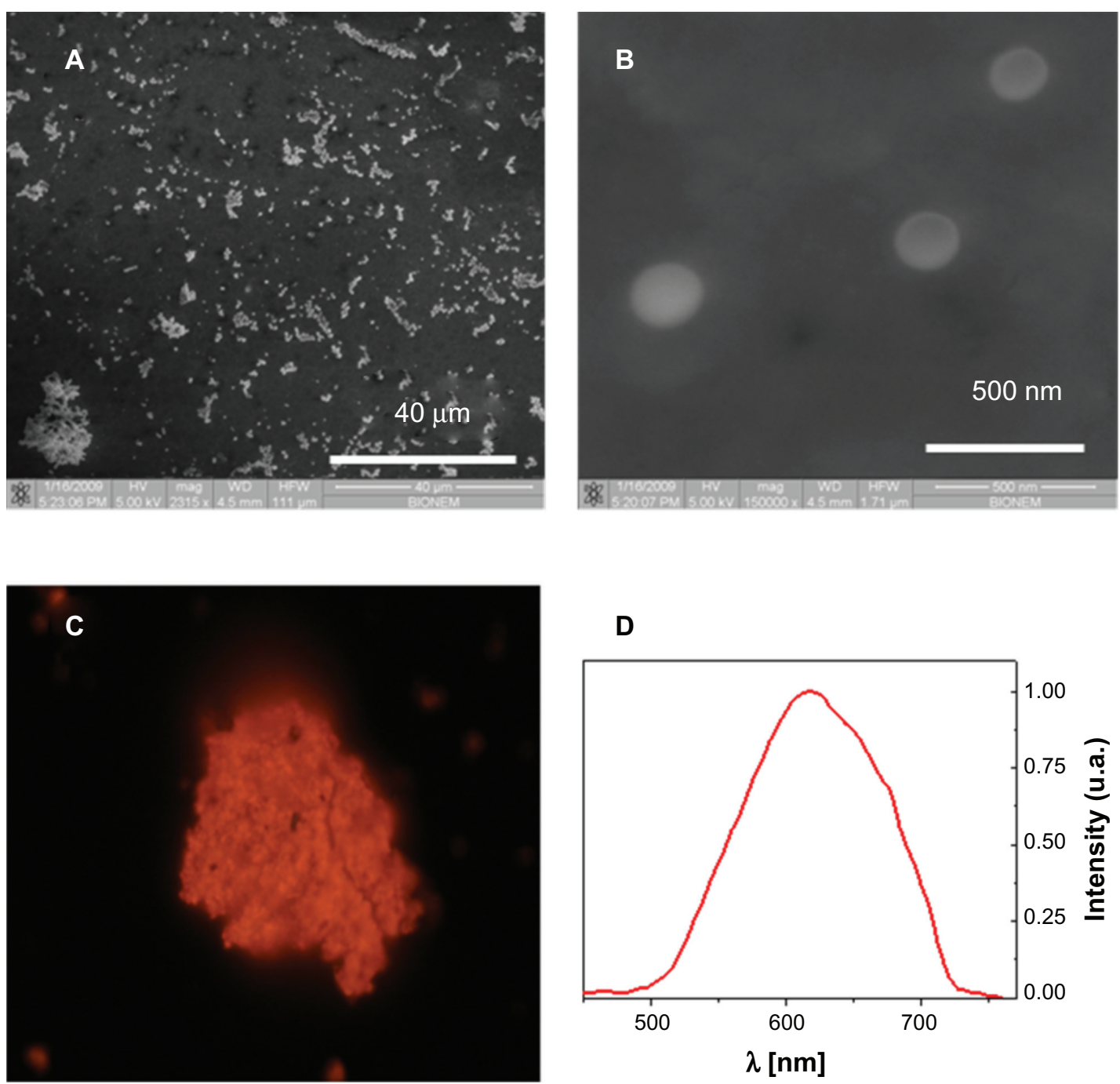

D

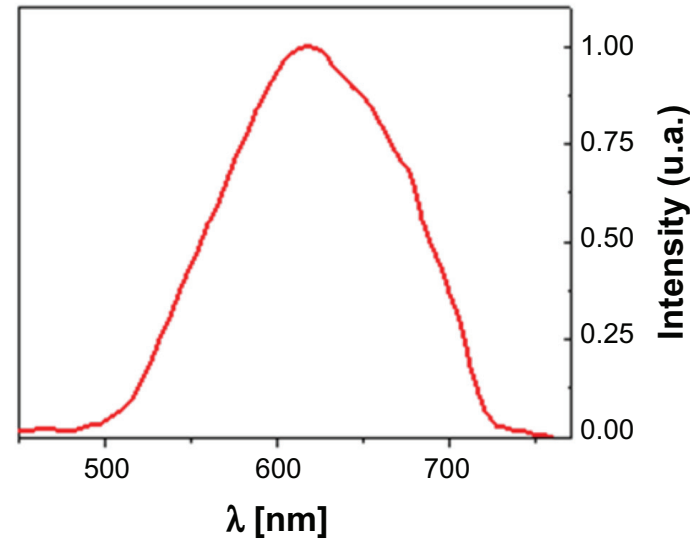

Figure 2 Nanoporous nanoparticles characterization. Scanning electron microscope images of nanoporous nanoparticles dried on a slide (panels A and B). The pores of the particles are too small to be shown, but the typical emission spectrum in red-orange band (panels $C$ and $D$ ) indicates a pore size of about $2-3$ nm (excitation wavelength $408 \mathrm{~nm})$.

the dissolution takes a few minutes, but it can be also carried out at room temperature in a few hours, if nondenaturing conditions are needed. At $\mathrm{pH}<5$, the NPNPs do not dissolve, allowing their long-term storage in water at or above room temperature.

In experiment 1 , the amount of harvested fraction of dextran-FITC (MW $6 \mathrm{kDa}$ ) can be evaluated by comparing the total fluorescence intensity of 2 solutions (harvested vs supernatant). The 2 solutions show very similar fluorescence intensity values, indicating that, under the experimental conditions described above, $50 \%$ of the molecules were harvested, whereas the remaining 50\% were left in solution. This result shows that the loading capacity is very high, about $1 \mathrm{mg}$ of harvested molecules for each mg of NPNPs.

In the second experiment, the ability of NPNPs to enrich the LMW fraction of a complex mixture was tested with an ad hoc protein mixture (see Materials and methods). For this purpose, the effects of several parameters such as $\mathrm{pH}$, osmolarity, temperature, and incubation time were studied, and conditions were optimized, and, finally, a volume of $200 \mathrm{~mL}$ of protein mixture was incubated with $5 \mathrm{mg}$ of NPNPs (about $10^{15}$ particles) at room temperature for 1 hour. NPNPs were subsequently separated from supernatant by centrifugation, and washed once with $\mathrm{PBC}$ buffer. The sodium dodecyl sulfate-PAGE (SDS-PAGE) in Figure 4 (panel A) clearly shows that nanoparticles selectively retain small molecules as aprotinin (MW 6,500 Da), whereas proteins with higher MW are completely excluded from the nanopores. We noted that during the incubation a small fraction of the nanoparticles dissolve releasing silicic acid into the solution (about $8 \%$ of NPNP volume under our conditions). ${ }^{26}$ This amount can be decreased by lowering 

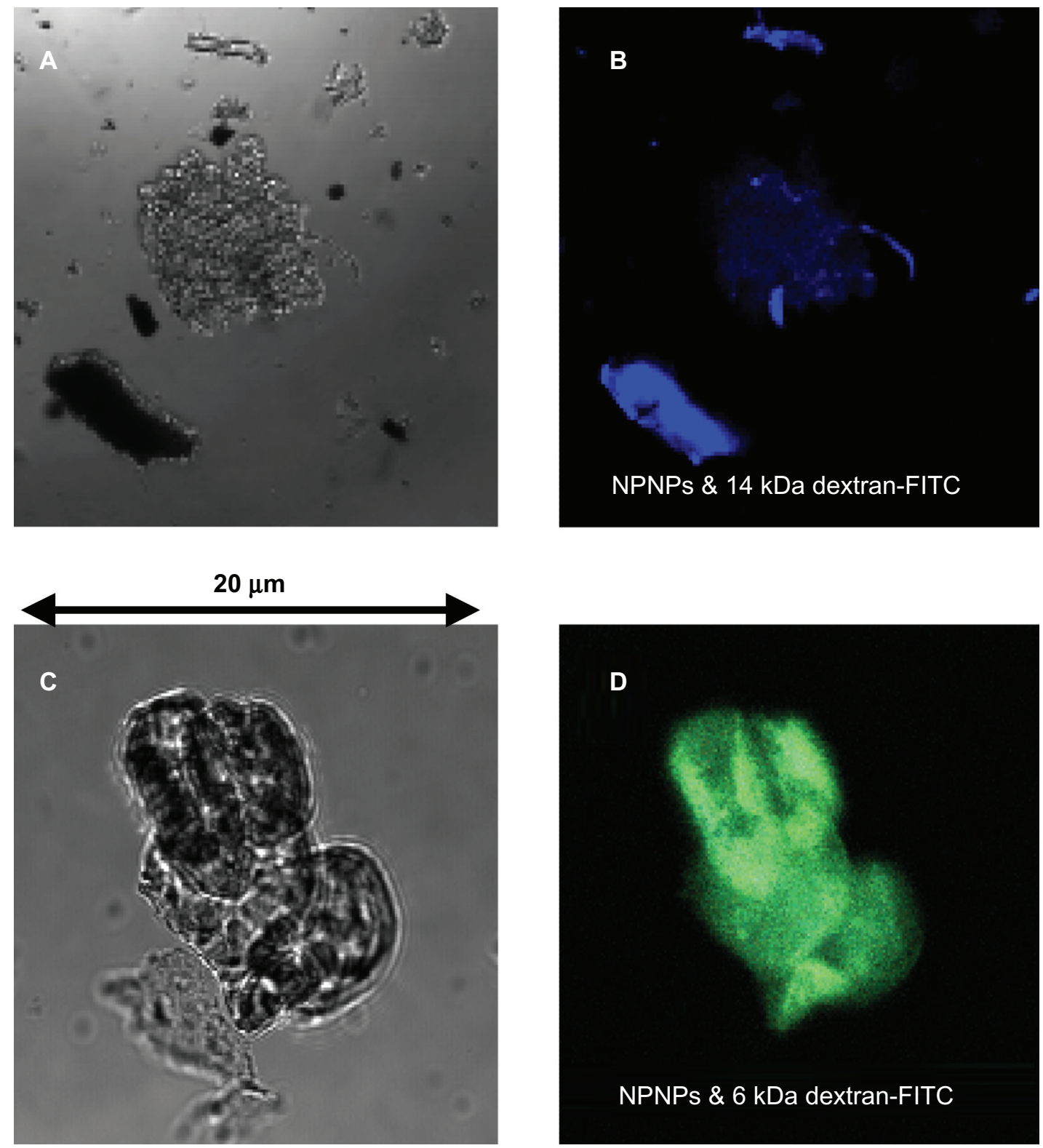

Figure 3 Optical and fluorescence images of the nanoporous nanoparticles (NPNPs) after incubation with 2 fluorescent polymers of different molecular weights (MWs): dextran-FITC $14 \mathrm{kDa}$ (panels A and B), and dextran-FITC $6 \mathrm{kDa}$ (panels C and D). The adsorption of the lighter polymer is clearly indicated by the green fluorescence emitted from the nanoparticles (panel D). In contrast, no green fluorescence can be observed being emitted from the heavier polymer (the blue fluorescence comes from salt residues), confirming the MW cut-off.

the incubation temperature, $\mathrm{pH}$, or incubation time when possible.

In the third experiment, the same protocol for experiment 2 was applied to raw human serum to demonstrate that NPNPs are able to selectively enrich LMW serum proteome (LMWP). After 1 hour of incubation $(100 \mathrm{~mL}$ of serum sample diluted 1:2 with PBC buffer, $5 \mathrm{mg}$ of NPNPs), the LMW fraction was recovered by dissolving the nanoparticles in PBC buffer for 12 hours at $37^{\circ} \mathrm{C}$. We noted that the dissolution process can be hastened by heating the solution and adding a base (to increase $\mathrm{pH}$ ) or other solvent.
An aliquot of serum, before and after incubation, was analyzed by SDS-PAGE using a $16.5 \%$ ready prepared tris-tricine/peptide gel. The efficiency of NPNPs to selectively enrich the LMWP is clearly demonstrated in the SDS-PAGE analysis shown in Figure 4 (panel B): in lines 2 and 3 , crude human serum and supernatant are represented. In line 4, the LMW fraction of human serum extracted from NPNPs is visible: no molecules $>12 \mathrm{kDa}$ are still present, except for a very small trace of albumin. From densitometric analysis of lane 4 , it was estimated that $>50 \%$ of total pixel volume was from LMW species, whereas in 

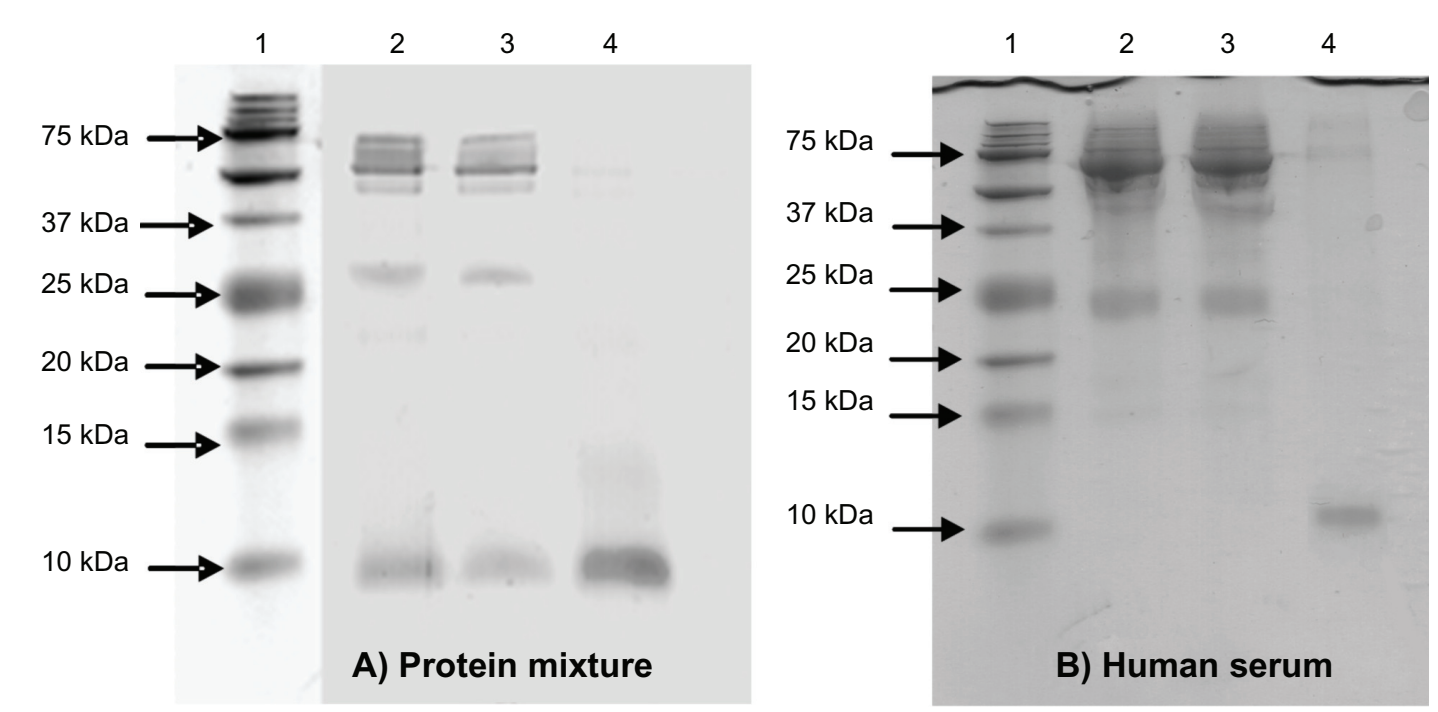

Figure 4 (A) The sodium dodecyl sulfate polyacrylamide gel electrophoresis (SDS-PAGE) analysis of protein mixture before and after incubation with nanoporous silicon particles. $100 \mathrm{~mL}$ of protein mixture (see text for details) was subjected to incubation with nanoparticles. Aliquots of the mixture before and after incubation were subjected to tris-tricine SDS-PAGE and stained with Coomassie Brilliant Blue. Lane I A: molecular weight markers; lane 2 A: protein mixture before incubation; lane 3 A: protein mixture following nanoparticle incubation (supernatant); lane $4 \mathrm{~A}$, low-molecular-weight (LMW) protein fraction enriched (pellet). (B) SDS-PAGE analysis of human serum before and after incubation with nanoporous silicon particles. Serum was diluted to $1: 2$ with $100 \mathrm{mM}$ sodium phosphate buffer, $9 \%$ ( $\mathrm{p} / \mathrm{v}$ ) sodium chloride, $\mathrm{pH} 7.4$, and incubated with nanoparticles. Aliquots of serum before and after incubation were subjected to tristricine SDS-PAGE and stained with Coomassie Brilliant Blue. Lane IB, molecular weight markers; lane $2 \mathrm{~B}$, crude human serum; lane $3 \mathrm{~B}$, human serum following nanoparticle incubation (supernatant); lane $4 \mathrm{~B}$, LMW serum fraction enriched using (nondenaturing conditions) nanoporous silicon particles (pellet).

lane 2 (unprocessed serum) the same area represented $<1 \%$ of the total pixel volume. The enrichment factor was thus estimated to be $>50$.

In order to characterize the LMW protein species extracted by incubation with NPNPs, gel bands from SDS-PAGE-separated extracts (Figure 4b, lane 4) were cut and processed for tryptic digestion according to the protocol shown in the Supplementary Information, section 1. Based on MW marker information, the 3 processed gel bands corresponded to $\mathrm{MW}$ intervals of 15-20 kDa, 10-15 kDa and $<10 \mathrm{kDa}$. Tryptic peptides were analyzed by nanoscale liquid chromatography interfaced with tandem MS (nanoLC-MS/MS, Supplementary Information, section 2). ${ }^{27,28}$ In an alternative approach, proteins extracted by incubation with NPNPs were directly digested in solution by trypsin and analyzed by nanoLC-MS/MS. Validated protein identifications are reported in 2 tables (Supplementary Information, section 3). Besides abundant LMW serum proteins, such as apolipoprotein A-II and transthyretin, a database search identified a number of LMW serum proteins that are not considered abundant, such as tetranectin, platelet basic protein, and dermcidin. Furthermore, LC-MS/MS analysis identified several high-MW proteins in the in-gel-digested SDS-PAGE protein bands. Such identifications confirm that the LMW proteome is also populated with fragments of abundant high-MW serum proteins. ${ }^{29}$
A comparison of the results of these experiments with those reported in the literature shows many remarkable characteristics of the NPNPs:

1. easy and cheap production.

2. controllable pore size and well known surface chemistry.

3. small molecules can be absorbed with a tuneable MW cut-off.

4. biocompatibility and biodegradability in physiological solution.

5. easy recovery by centrifugation,

6. long-term storage wet (water solution of $\mathrm{pH}<5$ ) or dry. We note that such properties are very attractive also for drug delivery applications, for which the use of nanocarriers is attracting a lot of interest.

\section{Conclusion}

We report a straightforward tool relying on water-soluble silicon NPNPs used to harvest the LMW molecules in their native state from a complex fluid. The method is based on the porosity of the nanoparticles, which act as a molecular sieve, and their solubility in a physiological environment. The proposed approach can be mixed and matched with currently available techniques and protocols, and does not require high temperature, denaturing solvents, or other contaminants. A cut-off of about $13 \mathrm{kDa}$ was demonstrated for crude human serum. The ability to tune pore size, combined with the 
availability of hundreds of biomolecule cross-linkers, opens up new perspectives on complex biofluid analysis, discovery of biomarkers, and in situ drug delivery.

\section{Disclosure}

The authors declare that they have no competing interests. Giovanni Cuda and Enzo Di Fabrizio equally share the senior authorship. They conceived the study, and participated in its design and coordination and helped to draft the manuscript. Antonella Pujia was involved in the fabrication of NPNPs and carried out the harvesting experiments; Francesco De Angelis contributed to the design of NPNPs and to the drafting of the manuscript; Domenica Scumaci carried out gel electrophosesis experiments; Marco Gaspari was involved in the mass spectrometry analysis; Carlo Liberale contributed to the design and fabrication of NPNPs; and Patrizio Candeloro contributed to the design of NPNPs and to the analysis of experimental data.

\section{References}

1. Anderson NL, Anderson NG. The human plasma proteome: history, character, and diagnostic prospects. Mol Cell Proteomics. 2002;1(11):845-867.

2. Hanash SM, Pitteri SJ, Faca VM. Mining the plasma proteome for cancer biomarkers. Nature. 2008;452:571-579.

3. Issaq HJ, Xiao Z, Veenstra TD. Serum and plasma proteomics. Chem Rev. 2007;107:3601-620.

4. Kulasingam V, Diamandis EP. Strategies for discovering novel cancer biomarkers through utilization of emerging technologies. Nature Clin Pract Oncol. 2008;5:588-599.

5. Minden JS, Dowd SR, Meyer HE, et al. Difference gel electrophoresis. Electrophoresis. 2009;30 Suppl 1:S156-S161.

6. Görg A, Drews O, Lück C, et al. 2-DE with IPGs. Electrophoresis. 2009;30 Suppl 1:S122-S132.

7. Diamandis EP, Hanash SM, Lopez M, et al. Protein quantification by mass spectrometry: is it ready for prime time? Clin Chem. 2009;55:1427-1430.

8. Motoyama A, Yates JR. Multidimensional LC separations in shotgun proteomics. Anal Chem. 2008;80:187-193.

9. Liao L, McClatchy DB, Yates JR. Shotgun proteomics in neuroscience. Neuron. 2009;63:12-26.

10. Sahab ZJ, Iczkowski KA, Sang QX. Anion exchange fractionation of serum proteins vs albumin elimination. Anal Biochem. 2007;368(1):24-32.

11. Rothemund DL, Locke VL, Liew A, et al. Depletion of the highly abundant protein albumin from human plasma using the Gradiflow. Proteomics. 2003;3:279-287.
12. Yocum AK, Yu K, Oe T, et al. Effect of immunoaffinity depletion of human serum during proteomic investigations. J Proteome Res. 2005;4(5):1722-1731.

13. Luchini L, Geho DH, Bishop B, et al. Smart hydrogel particles: biomarker harvesting: one-step affinity purification, size exclusion, and protection against degradation. Nano Lett. 2008;8(1):350-361.

14. Fu J, Mao P, Han J. Artificial molecular sieves and filters: a new paradigm for biomolecule separation. Trends Biotechnol. 2008;26:311-320.

15. Cheng MM, Cuda G, Bunimovich YL, et al. Nanotechnologies for biomolecular detection and medical diagnostics. Curr Opin Chem Biol. 2006;10:11-19.

16. Chunxiong L, Qiang F, Hao L, et al. PDMS microfluidic device for optical detection of protein immunoassay using gold nanoparticles. $L a b$ Chip. 2005;5:726-729.

17. Canham LT. Bioactive silicon structure fabrication through nanoetching techniques. Adv Mater. 1995;7:1033-1037.

18. Anderson SHC, Elliott H, Wallis DJ, et al. Dissolution of different forms of partially porous silicon wafers under simulated physiological conditions. Phys Stat Sol (a). 2003;197:331-335.

19. Vaccari L, Canton D, Zaffaroni N, et al. Porous silicon as drug carrier for controlled delivery of doxorubicin anticancer agent. Microelectronic Eng. 2006;83:1598-1601.

20. Canham LT, Reeves CL, Newey JP, et al. Derivatized mesoporous silicon with dramatically improved stability in simulated human blood plasma. Adv Mater. 1999;11:1505-1507.

21. Song JH, Sailor MJ. Chemical modification of crystalline porous silicon surfaces. Comm Inorg Chem. 1999;21:69-84.

22. Tinsley-Bown AM, Canham LT, Hollings M, et al. Tuning the pore size and surface chemistry of porous silicon for immunoassays. Physica Status Solidi A Appl Res. 2000;182:547-553.

23. Akcakir O, Therrien J, Belomoin G, et al. Detection of luminescent single ultrasmall silicon nanoparticles using fluctuation correlation spectroscopy. Appl Phys Lett. 2000;76:1857-1859.

24. Froner E, Adamo R, Gaburr Zo, et al. Luminescence of porous silicon derived nanocrystals dispersed in water: dependence on initial porous silicon oxidation. J Nanopart Res. 2006;8:1071-1074.

25. Tirumalai RS, Chan KC, Prieto DA, et al. Characterization of the low molecular weight human serum proteome. Mol Cell Proteomics. 2003;2:1096-1103.

26. Anglin EJ, Cheng L, Freeman WR, et al. Porous silicon in drug delivery devices and materials. Adv Drug Deliv Rev. 2008;60:1266-1277.

27. Meiring HD, van der Heeft E, ten Hove GJ, et al. Nanoscale LC-MS ${ }^{(n)}$ : technical design and applications to peptide and protein analysis. $J \mathrm{Sep}$ Sci. 2002;25:557-568.

28. Gaspari M, Abbonante V, Cuda G. Gel-free sample preparation for the nanoscale LC-MS/MS analysis and identification of low-nanogram protein samples. J Sep Sci. 2007;30:2210-2216.

29. Rai AJ, Gelfand CA, Haywood BC, et al. HUPO plasma proteome project specimen collection and handling: towards the standardization of parameters for plasma proteome samples. Proteomics. 2005;5(13):3262-3277. 


\section{Supplementary information In-gel digestion}

Gel bands below $25 \mathrm{kDa}$ were excised and digested by trypsin incubation; selected bands were punched out manually and placed in a silicon Eppendorf tube. Gel pieces were washed once with $150 \mathrm{~mL}$ of deionized water and

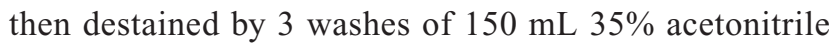
in $25 \mathrm{mM} \mathrm{NH} 4 \mathrm{HCO}_{3}$ buffer. After destaining, trypsin digestion was performed overnight at $37^{\circ} \mathrm{C}$ with modified trypsin (Sigma-Aldrich, St Louis, MO, USA) $0.2 \mathrm{mg} / \mathrm{mL}$. The resulting tryptic peptides were acidified, purified by Ziptips C18 (Millipore, Billerica, MA) according to the manufacturer's procedure and eluted with $2 \mu \mathrm{L}$ of a $1: 1$ mixture of acetonitrile and $0.1 \%$ trifluoro acetic acid (v/v). $28 \mu \mathrm{L}$ of loading pump solvent (see below) were added, and $10 \mu \mathrm{L}$ were injected for nanoLC-MS/MS analysis.

\section{In-solution digestion}

Protein extracts were reduced by $2 \mathrm{mM}$ DTT ( 1 hour at $37^{\circ} \mathrm{C}$ ). $500 \mathrm{ng}$ of sequencing grade modified trypsin (Sigma-Aldrich) were added, and digestion was allowed to proceed for $16 \mathrm{~h}$. The resulting tryptic peptides were fractionated by Off-Gel eletrophoresis before nanoscale LC-MS/MS analysis, in order to achieve a 2-dimensional fractionation of the peptide mixture. An Agilent 3100 Off-Gel fractionator (Agilent Technologies, Santa Clara, CA) was used. Off-Gel isoelectric focusing was essentially peformed according to the manufacturer's instructions. The peptide mixture was diluted with carrier ampholyte mixture $(3.6 \mathrm{~mL}$ final volume, $10 \%$ carrier ampholyte concentration). The sample was then loaded on separate Immobiline $^{\mathrm{TM}}$ DryStrip, linear $\mathrm{pH}$ range $3.0-10,18 \mathrm{~cm}$ long, purchased from GE Healthcare (Chalfont St. Giles, UK). Peptides were focused at a constant temperature of $20^{\circ} \mathrm{C}$, and at constant current intensity of $50 \mu \mathrm{A}$. After focusing was complete, fractions were collected. In order to improve peptide recovery, sample wells were washed with $100 \mu \mathrm{L}$ of a water/methanol/formic acid mixture, 49:50:1 (v/v/v). The wash solution was added to each well and allowed to incubate for 90 minutes before being collected and pooled with the corresponding fraction supernatant. Pooled supernatants were reduced to a volume of approximately $10 \mu \mathrm{L}$ in a vacuum centrifuge.
A 1:4 mixture of concentrated eluates and loading pump solvent of the nanoLC-MS/MS system (see below) was injected for nanoLC-MS/MS analysis. Considering the injection volume of $10 \mu \mathrm{L}$, approximately $1 / 5$ of each OGE fractions was injected for nanoLC-MS/MS.

\section{Nanoscale LC-MS/MS analysis}

Chromatography was performed on an Ultimate nanoLC system from Dionex (Sunnyvale, CA, USA), using a valveless setup. ${ }^{1,2}$ The peptide extracts were redissolved in $30 \mu \mathrm{L}$ of loading pump solvent (see below) and $10 \mu \mathrm{L}$ were loaded onto an in-house packed $100 \mu \mathrm{m}$ i.d., Integra Frit ${ }^{\mathrm{TM}}$ (New Objective, Cambridge, MA) trapping column (packing bed length $1.5 \mathrm{~cm}$ ) at $10 \mu \mathrm{L} / \mathrm{min}$ of loading pump solvent, consisting of $\mathrm{H}_{2} \mathrm{O} /$ acetonitrile/trifluoroacetic acid (TFA) 97.95:2:0.05 ( $\mathrm{v} / \mathrm{v} / \mathrm{v})$. After 4 minutes of column washing, the trapping column was switched on-line to the analytical column: an in-house packed $50 \mu \mathrm{m}$ i.d., Pico Frit ${ }^{\mathrm{TM}}$ column (New Objective), filled with the same stationary phase used for the trapping column packing: $3 \mu \mathrm{m} \mathrm{C}_{18}$ silica particles (Dr Maisch, Entringen, Germany). Peptide separation started at $100 \mathrm{~nL} / \mathrm{min}$ using a binary gradient. Mobile phase A was $\mathrm{H}_{2} \mathrm{O} /$ acetonitrile/formic acid/TFA 97.9:2:0.09:0.01 (v/v/v/v); mobile phase $\mathrm{B}$ was $\mathrm{H}_{2} \mathrm{O}$ /acetonitrile/formic acid/TFA 29.9:70:0.09:0.01 (v/v/v/v). Gradient was from 5 to $45 \%$ B in 40 minutes. After 10 minutes at $95 \% \mathrm{~B}$, the column was re-equilibrated at $5 \% \mathrm{~B}$ for 20 minutes before the following injection.

MS detection was performed on a QSTAR XL hybrid LC-MS/MS from Applied Biosystems (Foster City, CA, USA) operating in positive ion mode, with nESI potential at $1300 \mathrm{~V}$, curtain gas at 15 units, CAD gas at 3 units. Information-dependent acquisition (IDA) was performed by selecting the 2 most abundant peaks for MS/MS analysis after a full TOF-MS scan from 400 to $1600 \mathrm{~m} / \mathrm{z}$ lasting 4 seconds. Both MS/MS analyses were performed in enhanced mode (3 seconds/scan). Threshold value for peak selection for MS/MS was 30 counts.

\section{Data analysis}

MS/MS data were converted to Mascot Generic Format (mgf) by the Analyst software 1.1 (Applied Biosystems). Data were searched on the Mascot search engine (www.matrixscience.com), version 1.9, against the International Protein Index database (IPI version 3_38) 
using the following parameters: MS tolerance $30 \mathrm{ppm}$; MS/ MS tolerance $0.2 \mathrm{Da}$; variable modifications methionine oxidized; enzyme trypsin; max. missed cleavages 1 . MS/ MS identifications were validated by using the transproteomics pipeline. ${ }^{3}$ Peptide identifications with a minimum probability score of 0.7 were retained ( $4 \%$ false discovery rate). Proteins identified with a minimum of 2 peptides were retained (protein probability score $>0.9$ ). Protein identifications based on a single peptide were manually validated.

Table I Proteins identified by in-gel digestion and nanoLC-MS/MS of SDS-PAGE-isolated bands

\begin{tabular}{|c|c|c|c|c|c|c|}
\hline $\begin{array}{l}\text { Accession } \\
\text { number }\end{array}$ & Protein description & $\begin{array}{l}\text { Theoretical } \\
\text { Mw }\end{array}$ & $\begin{array}{l}\text { No. unique } \\
\text { peptides }\end{array}$ & Probability & $\begin{array}{l}\text { Mascot } \\
\text { score* }\end{array}$ & $\begin{array}{l}\text { Sequence } \\
\text { coverage }\end{array}$ \\
\hline IPI00022434 & ALB Uncharacterized protein & 71.6 & 45 & I & - & 67.5 \\
\hline IPI0002I84I & ALB apoliprotein a I & 30.8 & 25 & I & - & 72.0 \\
\hline IPI0002। 885 & $\begin{array}{l}\text { FGA Isoform I of Fibrinogen } \\
\text { alpha chain precursor }\end{array}$ & 94.9 & 15 & I & - & 19.7 \\
\hline IPI00304273 & $\begin{array}{l}\text { APOA4 Apolipoprotein A-IV } \\
\text { precursor }\end{array}$ & 45.3 & 13 & 1 & - & 34.1 \\
\hline IPI0002237I & $\begin{array}{l}\text { HRG Histidine-rich } \\
\text { glycoprotein precursor }\end{array}$ & 59.5 & 11 & I & - & 24.8 \\
\hline IPI00553I77 & $\begin{array}{l}\text { Isoform I of Alpha-I- } \\
\text { Antitrypsin }\end{array}$ & 46.7 & 10 & I & - & 24.2 \\
\hline IPI0002I842 & $\begin{array}{l}\text { APOE Apolipoprotein E } \\
\text { precursor }\end{array}$ & 36.1 & 10 & I & - & 36.0 \\
\hline IPI00783987 & C3 Complement & 187.0 & 9 & 1 & - & 4.5 \\
\hline IPI00399007 & $\begin{array}{l}\text { IGHG2 Putative uncharacterized } \\
\text { protein DKFZp686104I } 96 \\
\text { (Fragment) }\end{array}$ & 46.0 & 5 & 1 & - & 14.1 \\
\hline IPI004|9424 & IGKVI-5 IGKVI-5 protein & 26.2 & 5 & I & - & 32.5 \\
\hline IPI008559I6 & Transthyretin & 15.9 & 4 & I & - & 48.0 \\
\hline IPI0002I855 & APOCI Apolipoprotein CI & 9.3 & 3 & 0.996 & - & 24.0 \\
\hline IPI00032258 & Complement c4 & 192.6 & 3 & 1 & - & 2.5 \\
\hline IPI0006| 977 & $\begin{array}{l}\text { IGHV3ORI6-I3;IGHAI IGHAI } \\
\text { protein }\end{array}$ & 54.1 & 2 & 0.999 & - & 5.0 \\
\hline IPI00022488 & $\begin{array}{l}\text { HPX Hemopexin } \\
\text { precursor }\end{array}$ & 51.6 & 2 & 0.983 & - & 4.1 \\
\hline IPI00I54742 & IGL@ IGL@ protein & 24.7 & 2 & 0.999 & - & 10.7 \\
\hline IPI000I9399 & $\begin{array}{l}\text { SAA4 Serum amyloid A-4 } \\
\text { protein precursor }\end{array}$ & 14.8 & 2 & 0.998 & - & 8.5 \\
\hline IPI0029897| & $\begin{array}{l}\text { VTN Vitronectin } \\
\text { precursor }\end{array}$ & 54.2 & 2 & 0.995 & - & 5.4 \\
\hline IPI0002/857 & APOC3 Apolipoprotein C3 & 12.8 & I & & 123 & 16.0 \\
\hline IPI0002I856 & $\begin{array}{l}\text { APOC2 Apolipoprotein C-II } \\
\text { precursor }\end{array}$ & 11.3 & I & & 42 & 10.0 \\
\hline IPI0043I645 & HP protein & 31.6 & 1 & & 30 & 9.0 \\
\hline IPI000I9038 & LYZ Lysozyme C precursor & 16.9 & I & & 73 & 8.0 \\
\hline IPI000263|4 & $\begin{array}{l}\text { GSN Isoform I of Gelsolin } \\
\text { precursor }\end{array}$ & 86.0 & 1 & & 27 & 1.0 \\
\hline IPI00298497 & $\begin{array}{l}\text { FGB Fibrinogen beta chain } \\
\text { precursor }\end{array}$ & 56.5 & I & & 43 & 3.0 \\
\hline IPI00032328 & $\begin{array}{l}\text { KNGI Isoform HMW } \\
\text { of Kininogen-I } \\
\text { precursor }\end{array}$ & 72.3 & I & & 34 & 1.0 \\
\hline
\end{tabular}

Notes: In gray, protein identification obtained with a single hit. Those hits were validated by visual inspection. MS/MS data are reported in Supplementary Information. Mascot score $(*)$ is reported for identifications which have not passed TPP validation, but were above Mascot threshold of 29 and for which manual validation was undertaken. 
Table 2 Additional proteins identified by direct in-solution digestion of silicon nanopraticle extracts

\begin{tabular}{|c|c|c|c|c|c|c|}
\hline $\begin{array}{l}\text { Accession } \\
\text { number }\end{array}$ & Protein description & $\begin{array}{l}\text { Theoretical } \\
\text { Mw }\end{array}$ & $\begin{array}{l}\text { No. unique } \\
\text { peptides }\end{array}$ & Probability & $\begin{array}{l}\text { Mascot } \\
\text { score* }\end{array}$ & $\begin{array}{l}\text { Sequence } \\
\text { coverage }\end{array}$ \\
\hline IPI004726I0 & IGHM IGHM protein & 52633 & 16 & I & - & 18 \\
\hline IPI00022229 & Apolipoprotein B-100 & 515.2 & 16 & I & - & 3.6 \\
\hline IPI00448925 & IGHGI IGHGI protein & 60064 & 15 & I & - & 15 \\
\hline IPI00478003 & A2M Alpha-2-macroglobulin & 163175 & 13 & I & - & 10 \\
\hline IPI00022463 & TF Serotransferrin precursor & 77.0 & 13 & I & - & 24.5 \\
\hline IPI0042605I & $\begin{array}{l}\text { Putative uncharacterized } \\
\text { protein DKFZp } 686 \mathrm{Cl} 52 / 3\end{array}$ & 51066 & 10 & 1 & - & 13 \\
\hline IPI00639937 & CFB B-factor, properdin & 85.4 & 9 & I & - & 9.7 \\
\hline IPI0002I89| & $\begin{array}{l}\text { FGG Isoform Gamma-B of } \\
\text { Fibrinogen gamma chain }\end{array}$ & 51479 & 8 & 1 & - & II \\
\hline IPI00I66866 & $\begin{array}{l}\text { IGHV3ORI6-I3; IGHAI IGHAI } \\
\text { protein }\end{array}$ & 53342 & 8 & I & - & 10 \\
\hline IPI0002/857 & APOC3 Apolipoprotein C-III & 10846 & 8 & I & - & 30 \\
\hline IPI00382938 & IGLV4-3 IGLV4-3 protein & 25961 & 6 & I & - & 20 \\
\hline IPI00022229 & APOB Apolipoprotein B-100 & $5|524|$ & 5 & I & - & 1 \\
\hline IPI0029|262 & CLU Clusterin precursor & 52.4 & 4 & 1 & - & 13.8 \\
\hline IPI00550640 & IGHG4 IGHG4 protein & 51953 & 4 & 1 & - & 5 \\
\hline IPI00328I03 & $\begin{array}{l}\text { KRT27 Keratin, type I } \\
\text { cytoskeletal } 27\end{array}$ & 49793 & 3 & 1 & - & 5 \\
\hline IPI000224I8 & FNI Isoform I of Fibronectin & 262442 & 3 & I & - & 2 \\
\hline IPI0054929| & IGHM IGHM protein & 66143 & 3 & I & - & 7 \\
\hline IPI002I7963 & $\begin{array}{l}\text { KRTI6 Keratin, type I } \\
\text { cytoskeletal I6 }\end{array}$ & 51236 & 3 & I & - & 4 \\
\hline IPI0002243I & $\begin{array}{l}\text { AHSG cDNA FLJ55606, highly } \\
\text { similar to Alpha-2-HS- } \\
\text { glycoprotein }\end{array}$ & 46597 & 3 & I & - & 4 \\
\hline IPI00555872 & $\begin{array}{l}\text { IGHV3-48 Myosin-reactive } \\
\text { immunoglobulin heavy chain } \\
\text { variable region (Fragment) }\end{array}$ & 12835 & 3 & I & - & 25 \\
\hline IPI0002/854 & $\begin{array}{l}\text { APOA2 Apolipoprotein A-II } \\
\text { precursor }\end{array}$ & 11.1 & 3 & I & - & 21.0 \\
\hline IPI00022445 & $\begin{array}{l}\text { PPBP Platelet basic protein } \\
\text { precursor }\end{array}$ & 13.8 & 2 & 0.999 & - & 19.5 \\
\hline IPI00009028 & CLEC3B Tetranectin & 22.5 & 2 & 0.999 & - & 10.4 \\
\hline IPI0002906I & SEPPI Selenoprotein $\mathrm{P}$ & 42.6 & 2 & 0.999 & - & 4.7 \\
\hline IPI000|958I & $\begin{array}{l}\text { Coagulation } \\
\text { factor XII precursor }\end{array}$ & 67.7 & 2 & I & - & 4.4 \\
\hline IPI00022420 & $\begin{array}{l}\text { RBP4 Plasma retinol binding } \\
\text { protein }\end{array}$ & 22.9 & 2 & 0.999 & - & 10.1 \\
\hline IPI00027547 & DCD Dermcidin precursor & 11.3 & 2 & 0.999 & - & 20 \\
\hline IPI000I760I & CP Ceruloplasmin & 122128 & 2 & 0.999 & - & I \\
\hline IPI000277I8 & $\begin{array}{l}\text { EVC Ellis-van Creveld } \\
\text { syndrome protein }\end{array}$ & 111920 & 2 & 0.999 & - & I \\
\hline IPI00009867 & $\begin{array}{l}\text { KRT5 Keratin, type II } \\
\text { cytoskeletal } 5\end{array}$ & 62340 & 2 & 0.999 & - & 1 \\
\hline IPI00382488 & $\begin{array}{l}\text { Ig heavy chain V-III region } \\
\text { HIL }\end{array}$ & 13557 & 2 & 0.999 & - & 13 \\
\hline IPI008I6799 & $\begin{array}{l}\text { Rheumatoid factor D5 light } \\
\text { chain (Fragment) }\end{array}$ & 12758 & 2 & 0.999 & - & 22 \\
\hline IPI00029739 & $\begin{array}{l}\text { CFH Isoform I of Complement } \\
\text { factor H precur }\end{array}$ & 139.0 & I & 0.992 & - & 0.9 \\
\hline IPI000|9568 & Prothrombin & 69.9 & I & 0.986 & - & 1.6 \\
\hline
\end{tabular}

(Continued) 
Table 2 (Continued)

\begin{tabular}{|c|c|c|c|c|c|c|}
\hline $\begin{array}{l}\text { Accession } \\
\text { number }\end{array}$ & Protein description & $\begin{array}{l}\text { Theoretical } \\
\text { Mw }\end{array}$ & $\begin{array}{l}\text { No. unique } \\
\text { peptides }\end{array}$ & Probability & $\begin{array}{l}\text { Mascot } \\
\text { score* }\end{array}$ & $\begin{array}{l}\text { Sequence } \\
\text { coverage }\end{array}$ \\
\hline IPI00009920 & $\begin{array}{l}\text { C6 Co (Complement } \\
\text { Component } 6 \\
\text { Precursor) }\end{array}$ & 105.6 & 1 & 0.972 & - & 1.9 \\
\hline IPI00298828 & $\begin{array}{l}\text { APOH Beta-2-glycoprotein I } \\
\text { precursor }\end{array}$ & 38.3 & 1 & 0.907 & - & 2.6 \\
\hline IPI000I959| & $\begin{array}{l}\text { cDNA FLJ55673, highly } \\
\text { similar to Complement factor B }\end{array}$ & 140853 & 1 & - & 45 & 1 \\
\hline IPI00008603 & $\begin{array}{l}\text { ACTA2 Actin, aortic smooth } \\
\text { muscle }\end{array}$ & 41982 & 1 & - & 41 & 2 \\
\hline IPI004| I626 & $\begin{array}{l}\text { FGG Putative uncharacterized } \\
\text { protein DKFZp779N0926 }\end{array}$ & 13979 & 1 & - & 42 & 6 \\
\hline IPI00382895 & UORF & 3952 & 1 & - & 43 & 29 \\
\hline IPI00022395 & C9 Complement component C9 & 63133 & 1 & - & 50 & I \\
\hline IPI00I66729 & $\begin{array}{l}\text { AZGPI alpha-2-glycoprotein I, } \\
\text { zinc }\end{array}$ & 34237 & 1 & - & 65 & 3 \\
\hline IPI00382478 & $\begin{array}{l}\text { Ig heavy chain V-III region } \\
\text { TIL }\end{array}$ & 12348 & 1 & - & 86 & 16 \\
\hline IPI0038440I & $\begin{array}{l}\text { Myosin-reactive } \\
\text { immunoglobulin kappa chain } \\
\text { variable region (Fragment) }\end{array}$ & 11754 & 1 & - & 110 & 16 \\
\hline IPI00385252 & $\begin{array}{l}\text { Ig kappa chain V-III region } \\
\text { GOL }\end{array}$ & 11823 & 1 & - & 125 & 16 \\
\hline
\end{tabular}

Notes: In gray, protein identification obtained with a single hit.

\section{References}

1. Meiring HD, van der Heeft E, ten Hove GJ, de Jong APJM, Sep J. Science. 2002;25:557-568.

2. Gaspari M, Abbonante V, Cuda G, Sep J. Science. 2007;30:2210-2216.
3. Keller A, Eng J, Zhang N, Li XJ, Aebersold R. Mol Syst Biol. 2005;1 msb4100024-E4100021-msb4100024E4100028 (2005).
International Journal of Nanomedicine

\section{Publish your work in this journal}

The International Journal of Nanomedicine is an international, peerreviewed journal focusing on the application of nanotechnology in diagnostics, therapeutics, and drug delivery systems throughout the biomedical field. This journal is indexed on PubMed Central, MedLine, CAS, SciSearch $\AA$, Current Contents ${ }^{\circledR} /$ Clinical Medicine,

\section{Dovepress}

Journal Citation Reports/Science Edition, EMBase, Scopus and the Elsevier Bibliographic databases. The manuscript management system is completely online and includes a very quick and fair peer-review system, which is all easy to use. Visit http://www.dovepress.com/ testimonials.php to read real quotes from published authors.

Submit your manuscript here: http://www.dovepress.com/international-journal-of-nanomedicine-journal 